\title{
Influence of Gender on Perception of Landscape: A Study of Viharamahadevi Park in Colombo
}

\author{
Perera D.*,Chandrasekara D.P. \\ University of Moratuwa, Sri Lanka. \\ *deemathi.perera@gmail.com
}

\begin{abstract}
This study investigates the influence of gender on perception of landscape, with reference to the Viharamahadevi Park in Colombo. The exiting literature suggests that there is a difference in perception of landscapes in reference to the gender of the user. Perception theories with emphases on visual perception aspect were identified through a literature survey. The identified visual perception theories were further analyzed in order to develop concepts and indicators. In spite of the transformation of 'green to grey' of most of the spaces in Colombo, Viharamahadevi park has preserved its landscape environment. Its location in the central part of Colombo has contributed to attract many different types of city dwellers and visitors. The presence of different visual landscape characters such as complexity, visual scale, stewardship, coherence and image ability at the Viharamahadevi Park lead to the selection of it the case study. A questionnaire was used to collect data from the general public (15 males and 15 females)who patronized the park regularly, and second year undergraduate students (15 male and 15 female students) following the degree of landscape architecture at Moratuwa University. The data was analyzed under the likerts scale.The analysis of data indicates that there is no clear difference of preference in landscapes between the female and male gender with the public users. The male gender of public who patronize the park has intention to interact with it, such as spend their time with nature or for relaxation. However, majority of the females of public use the park unintentionally due to social requirements. There is a significant difference in order of perception according to the gender among the second year undergraduate students. The information processing theory of visual perception explains the difference of visual landscape perception among landscape students and the general public. Landscape students have a comparatively better understanding on landscape than the general public. The knowledge supports them to have a clear visual perception, which coupled with gender orientations make a strong difference with male and female students. But due to the lack of higher level of ability to appreciate and understand the landscapes, the public do not have clear sense or a perception and thus lacks clear gender differences.
\end{abstract}

Keywords: Landscape, Visual perception, Gender

Proceedings of the International Forestry and Environment Symposium 2017 of the Department of Forestry and

Environmental Science, University of Sri Jayewardenepura, Sri Lanka 